\section{LA-UR-97- ${ }^{-} 328$}

Title:

Author(s):

Submitted to:

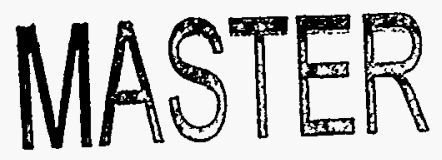

Los Alamos NATIONAL LABORATORY
CONE-970958-

Development of a 130-mA, $75-\mathrm{kV}$ High Voltage Column for High-Intensity dc Proton Injectors*

*Work performed under the auspices of the U.S.

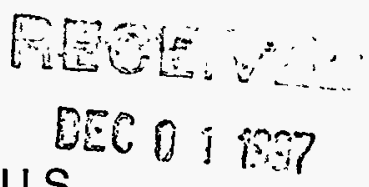

Department of Energy

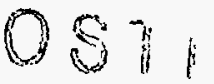

Joseph Sherman, Andy Arvin, Lash Hansborough, Dave Hodgkins, Earl Meyer, J. D. Schneider, R. R. Stevens, Jr., Thomas Zaugg

7th International Conference of Ion Sources

Taormina, Italy

September 7-13, 1997

\section{DSTRBUTION OF THIS DOCUMENT IS UNLMATED}

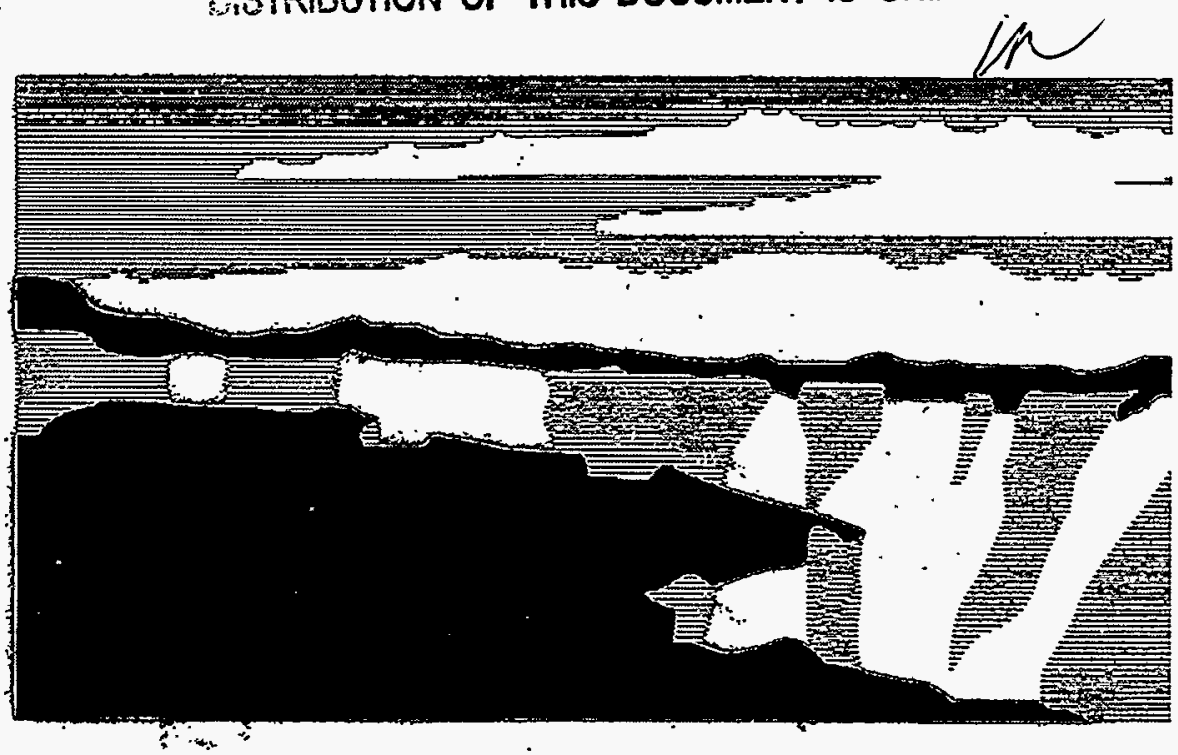

Los Alamos National Laboratory, an affirmative action/equal opportunity employer, is operated by the University of Califomia for the U.S. Department of Energy under contract W-7405-ENG-36. By acceptance of this article, the publisher recognizes that the U.S. Government retains a nonexclusive, royalty-free license to publlsh or reproduce the published form of this contribution, or to allow others to do so, for U.S. Govemment purposes. The Los Alamos National Laboratory requests that the publisher identify this article as work performed under the auspices of the U.S. Department of Energy. 


\section{DISCLAIMER}

This report was prepared as an account of work sponsored by an agency of the United States Government. Neither the United States Government nor any agency thereof, nor any of their employees, makes any warranty, express or implied, or assumes any legal liability or responsibility for the accuracy, completeness, or usefulness of any information, apparatus, product, or process disclosed, or represents that its use would not infringe privately owned rights. Reference herein to any specific commercial product, process, or service by trade name, trademark, manufacturer, or otherwise does not necessarily constitute or imply its endorsement, recommendation, or favoring by the United States Government or any agency thereof. The views and opinions of authors expressed herein do not necessarily state or reflect those of the United States Government or any agency thereof. 


\section{DISCLADIER}

Portions of this docoment may be illegible in electronic image products. Images are produced from the best available original doevonent 


\title{
Development of a 130-mA, 75-kV High Voltage Column for High-Intensity dc Proton Injectors
}

Joseph Sherman, Andrew Arvin, Lash Hansborough, Dave Hodgkins, Earl Meyer, J.

David Schneider, R. R. Stevens, Jr., and Thomas Zaugg

Los Alamos National Laboratory, Los Alamos, NM87545

\begin{abstract}
A reliable high-voltage (HV) column has been developed for dc proton injectors with applications to high-intensity $\mathrm{cw}$ linacs. The HV column is coupled with a microwavedriven plasma generator to produce a $75-\mathrm{keV}, 110-\mathrm{mA} \mathrm{dc}$ proton beam. Typical proton fraction from this source is $85-90 \%$, requiring the HV column and accelerating electrodes to operate with a 130-mA hydrogen-ion beam current. A glow-discharge, which was caused by the ion source axial magnetic field, was initially observed in the HV column. This problem was solved by scaling the electron production processes, the magnetic field, and the HV column pressure into a favorable regime. A subsequent 168 hour reliability run on the $75-\mathrm{keV}$ injector showed that the ion source (plasma generator and HV column) has $>98 \%$ beam availability.
\end{abstract}

\section{Introduction}

Development of a reliable HV structure to accelerate dc high-current $(>100 \mathrm{~mA})$ proton beams from an efficient microwave plasma generator is discussed here. This structure is an integral part of the proton injector being built for the $6.7 \mathrm{MeV}$ radio frequency quadrupole (RFQ) at Los Alamos ${ }^{2}$ for the low-energy demonstration accelerator (LEDA) project. ${ }^{3}$ The ion source generates a $75-\mathrm{keV}, 110-\mathrm{mA}$ proton beam for injection into the RFQ.

Figure 1 shows a $75 \mathrm{keV}$ PBGUNS simulation ${ }^{4}$ of a $129-\mathrm{mA}$ hydrogen-ion beam where $85 \%$ of the current is $\mathrm{H}^{+}$and $15 \% \mathrm{H}_{2}^{+}$, a proton fraction routinely obtained with the microwave proton source. ${ }^{5}$ The beam is formed at full energy in a single HV gap. The



Figure 1. PBGUNS simulation for a $129 \mathrm{~mA}, 75 \mathrm{keV}$ hydrogen-ion beam for the LEDA injector tetrode extraction system. The numeric labeling at the top of the figure refers to the nominal beam energy at each electrode. 
third electrode is an electron trap which stops backstreaming electrons from being accelerated to the plasma generator. The fourth electrode quickly establishes beam neutralization by limiting electric field extension into the transport region.

The first HV column showed a glow-discharge breakdown (BD) when the ion-source axial magnetic field was turned on in the presence of ion beam extraction voltage, which prevented reliable beam operations. A typical result from this early column operation is shown in Fig. 2, where the ion source solenoid 2 current is plotted vs. vacuum box $\mathrm{H}_{2}$ gas density for three values $(25,50$, and $75 \mathrm{kV})$ of the extractor voltage. Operation of magnetic fields greater than those shown in Fig. 2 led to a glow discharge, and subsequent $\mathrm{HV}$ breakdown. Even with no $\mathrm{H}_{2}$ gas flowing (at a box pressure of $3.7 \times 10^{-7}$ Torr) the initial HV column was unstable to HV BD with the ion source magnetic field on.

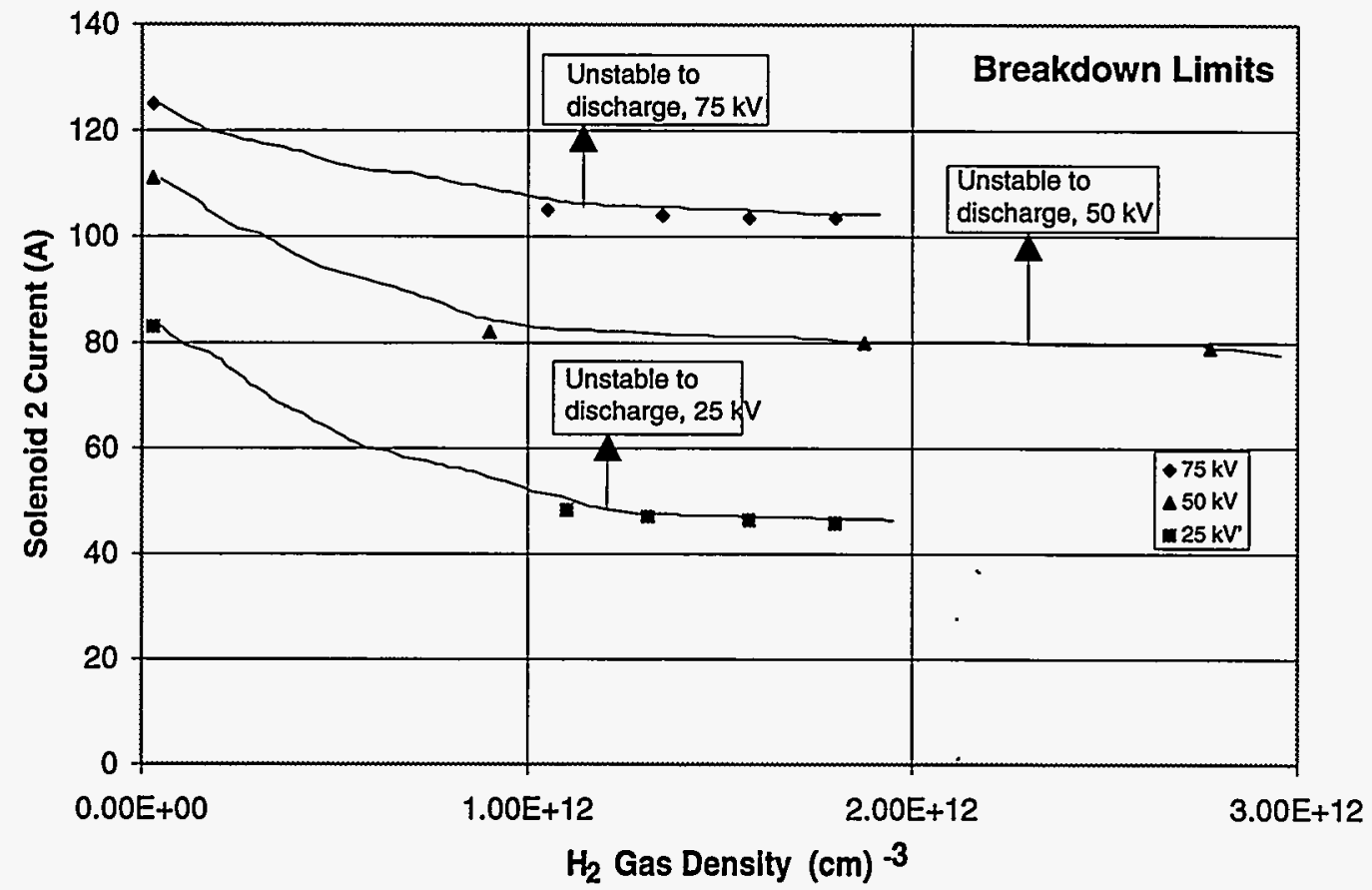

Figure 2. Limits of glow-discharge stability exhibited in an early version of the LEDA HV column.

This paper describes the physics and engineering design which led to a reliable HV column. The new column enabled a 168 hour reliability run ( 7 days, 24 hours/day) where the proton injector ran at LEDA RFQ beam requirements with $96 \%$ availability. Scaling parameters found ${ }^{6}$ to eliminate the $\mathrm{HV}$ instability are:

1. Reduction of electron producing processes in the HV column,

2. Ion source B-field reduction in the HV column, and,

3. Gas pressure reduction in the HV column.

Topics $1-3$ will be discussed followed by a summary section. It is emphasized that no single item in 1 - 3 led to acceptable HV column performance; each step improved the 
regions of stability shown in Fig. 2. Each HV column modification was required to improve the BD limits as outlined in Fig. 2, otherwise it was rejected. Mechanical engineering of this injector was discussed in an earlier paper.

\section{Reduction of Electron Production Within the HV Column}

Figure 3 shows a line drawing of the final $\mathrm{HV}$ design. The column is composed of two $\mathrm{Al}_{2} \mathrm{O}_{3}$ insulators (94\% alumina) $6.67 \mathrm{~cm}$ long and $40.64 \mathrm{~cm}$ inside diameter. The vacuum seal is made by O-ring compression on the ceramic end, which is $0.95 \mathrm{~cm}$ wide. This ceramic end is metallized to eliminate field enhancement at voids between the metal and ceramic surfaces. The extraction voltage is graded over the two ceramics by a cooled, $\mathrm{pH}$ controlled ( $400 \mathrm{~W}$ ) water resistor. The column resistance is adjusted to 15 $\mathrm{M} \Omega$ which allows $5 \mathrm{~mA}$ constant drain current. By comparison the beam impedance is $0.6 \mathrm{M} \Omega$.

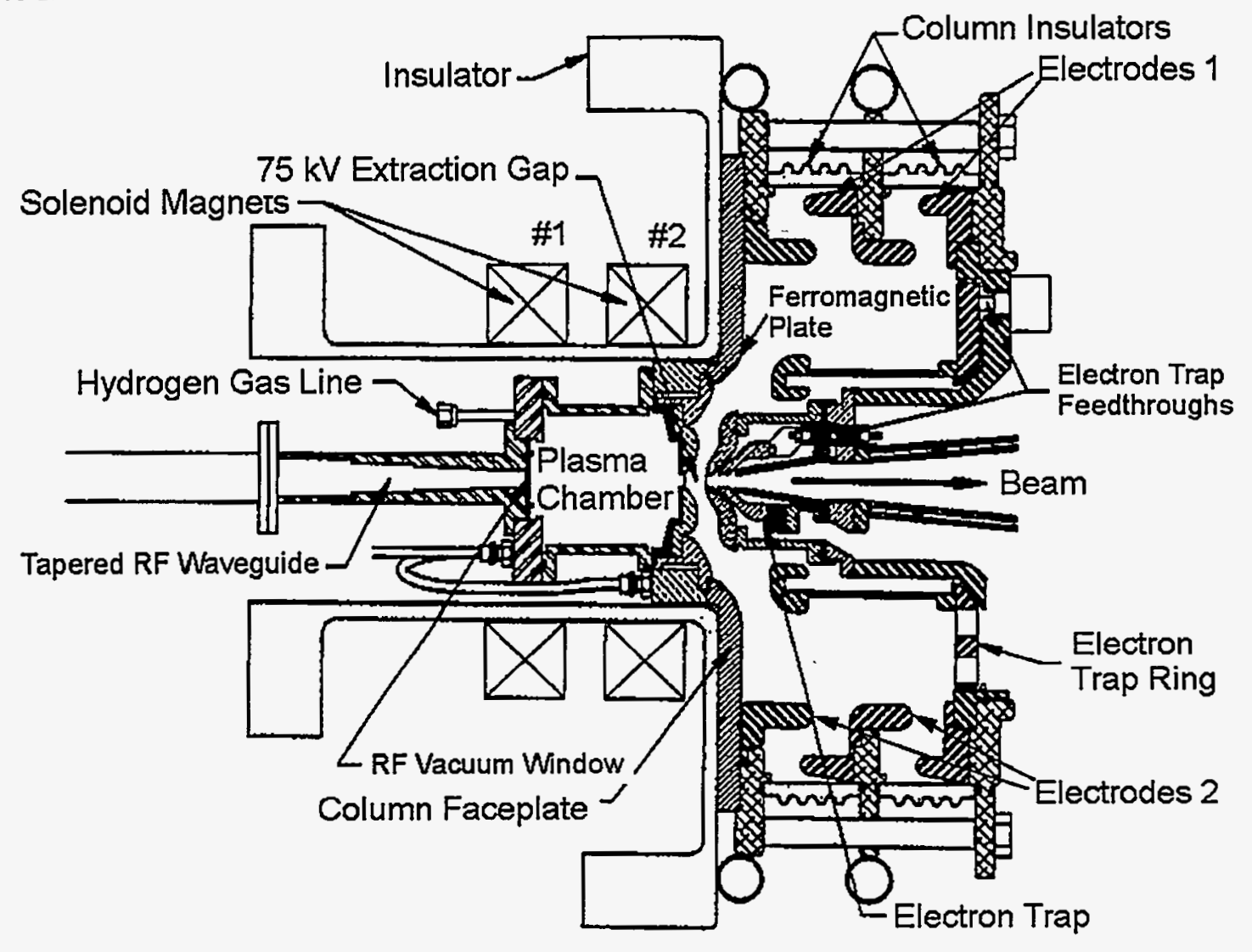

Figure 3. Line drawing of the LEDA injector ion source.

Electrodes 1 (cf. Fig. 3) are designed to reduce the electric field at the "negative triple junction" - the junction of ceramic, metal, and vacuum. The large increases in BD voltage (factor of 4 ) demonstrated ${ }^{8}$ by reducing the electric field at this junction is attributed to the reduction of field-emitted electrons by electric field reduction at the dielectric-metal interface. Figure 4 shows a POISSON model ${ }^{9}$ with a flat (A) and a shielded (B) termination of the ceramic insulator with the metal electrode. A reduction of 
about factor six in the axial electric field at the dielectric-metal interface is achieved. Note that the shielding is installed at the negative end of each ceramic ring.

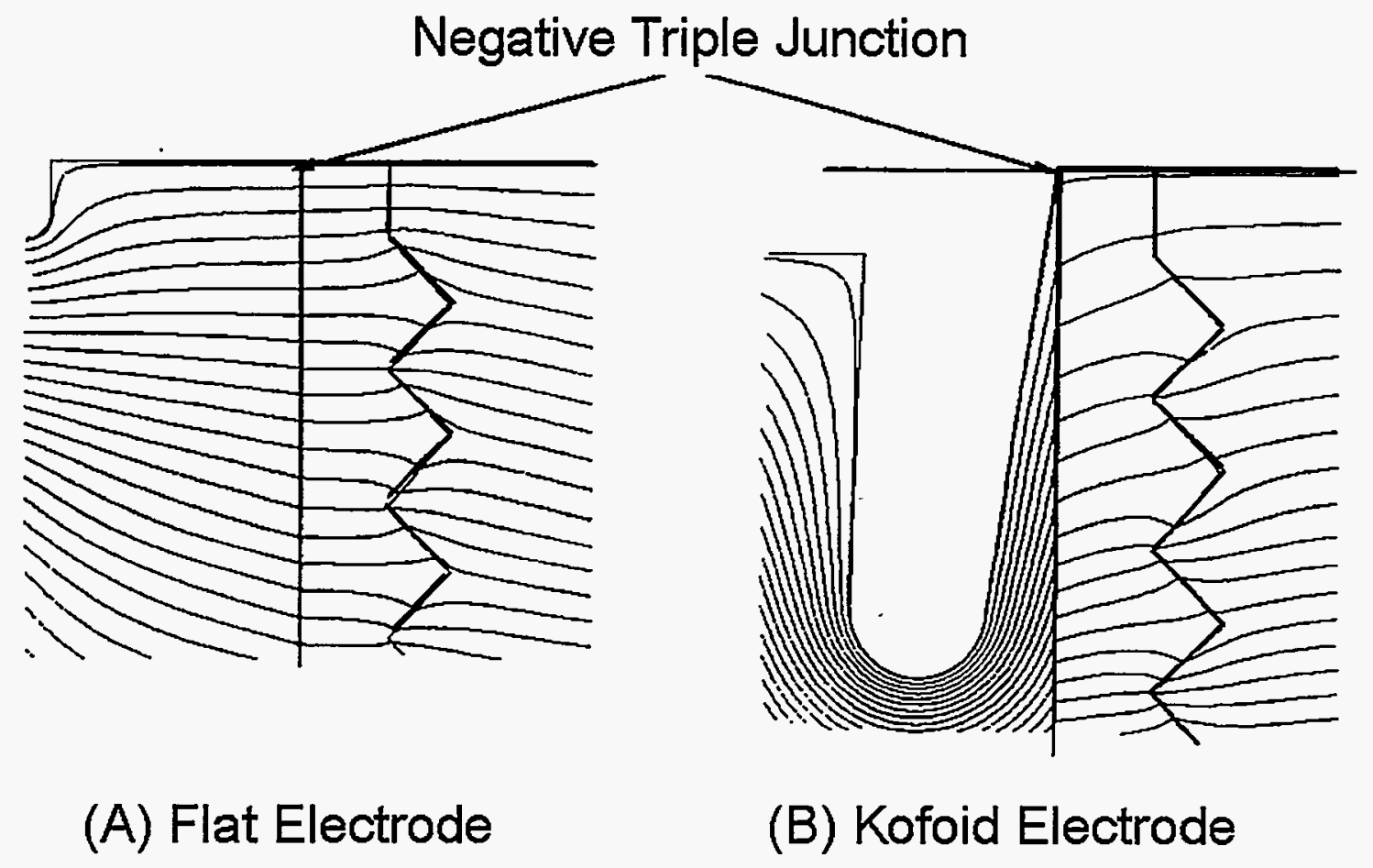

Figure 4. POISSON model calculations for the (A) unshielded and (B) shielded corners at the negative triple junction. Equipotential lines are shown superimposed on the electrode and ceramic structures.

Electrodes 2 (cf. Fig. 3) act together with electrodes 1 to shield the inner ceramic surface from line-of-sight bombardment by high-energy photons, electrons, or positive ions. Electrodes 1 and 2 are stainless steel approximately $1.6 \mathrm{~cm}$ thick, sufficient to attenuate $75 \mathrm{keV} x$ rays by a factor of $10^{5}$. X rays, produced by electrons backstreaming to an anode, produce photoelectrons when they strike the ceramic. The photoelectrons cascade along the ceramic surface with secondary electron emission, which may result in electron-avalanche induced $\mathrm{HV} \mathrm{BD} .^{10}$ Under electron bombardment, alumina ceramic has a maximum secondary emission yield of 9 as compared to 1.2 for stainless. ${ }^{11}$ Positive-ion interaction with insulators or contaminated metallic surfaces yield more secondary electrons than their interaction with a clean metallic surface. ${ }^{12}$

A third method of electron reduction is the installation of an electron trap ring (cf. Fig. 3) at the pump apertures located at the ground end of the HV column. The aspect ratio of the trap apertures is length/diameter $=1$, where the aperture diameter is $1.9 \mathrm{~cm}$. This ring operates at -1500 to $-2000 \mathrm{~V}$, and prevents electrons from the beam transport region reaching the $\mathrm{HV}$ column.

Free electrons within the HV column are thus reduced by shielding ceramics with metal electrodes and application of electrostatic electron traps. While we do not have a quantitative measure of the electron current reduction, $\mathrm{x}$-ray personnel radiation monitors now indicate $<5 \mathrm{mR} / \mathrm{hr}$ radiation at the injector high voltage barrier while the HV 
column is operating at $75 \mathrm{kV}, 130 \mathrm{~mA}$ hydrogen-ion beam. During the early stages of this HV column development, personnel exclusion barriers had to be installed in the column area because of the soft $\mathrm{x}$-ray radiation hazard.

\section{Ion Source B-Field Reduction}

The microwave proton source requires a $875 \mathrm{G}$ axial B-field to generate an electroncyclotron resonance (ECR) for plasma production. The ion source solenoids need 100 110 A current to establish this field without other magnetic material present. The proton beam is extracted coaxially with the magnetic field, resulting in relatively high $B$ fields throughout the HV column. Any electron with a velocity transverse to the B-field would undergo cycloidal motion, and its path length to an anode surface would be greatly enhanced thus allowing higher residual gas ionization. This effect is suppressed by changing the copper faceplate on the HV side of the HV column with a $1.6 \mathrm{~cm}$ thick ferromagnetic plate (cf. Fig. 3). This plate has a $13.3 \mathrm{~cm}$ diameter hole for mounting the ion source. A POISSON model for the B-field reduction is shown in Fig. 5. The calculations show a B-field reduction of $97 \%\left(\mathrm{~B}_{\mathrm{r}}\right)$ and $80 \%\left(\mathrm{~B}_{\mathrm{z}}\right)$ at a radius of $10.8 \mathrm{~cm}$.

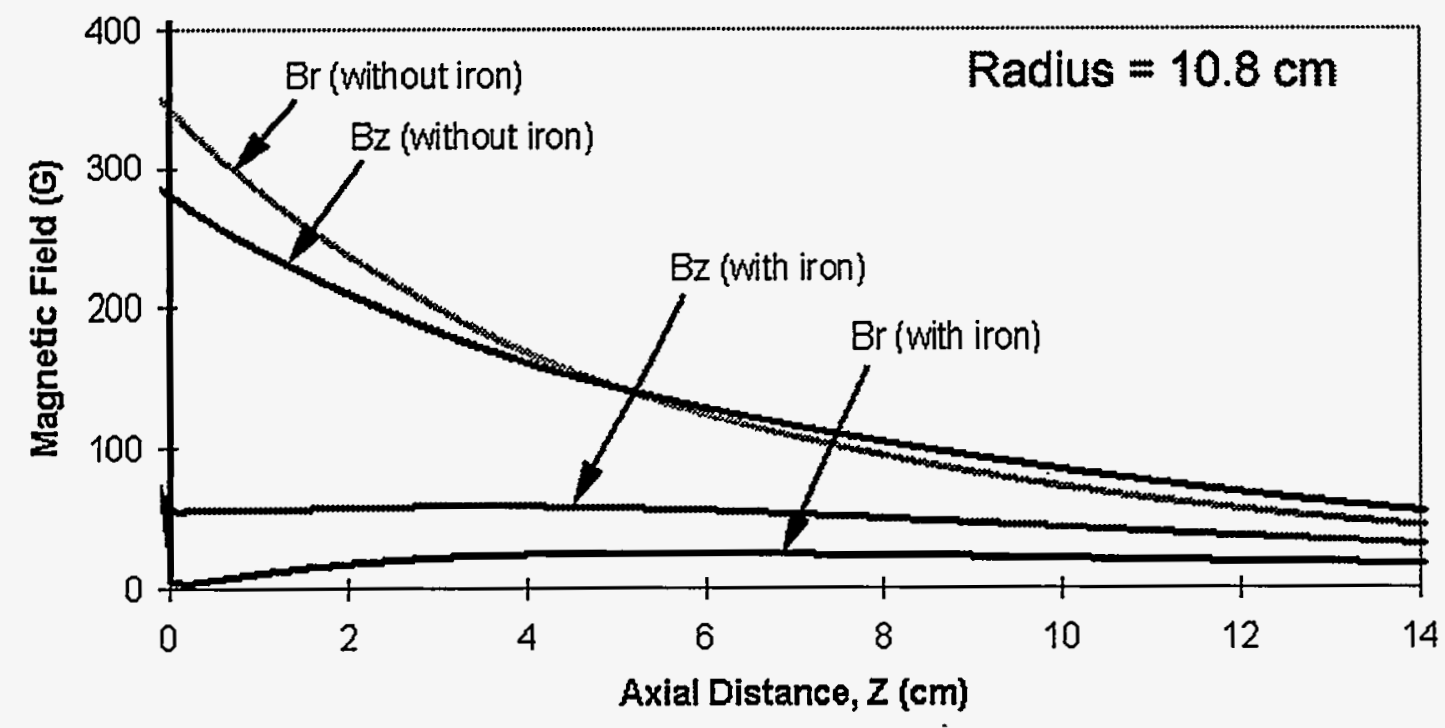

Figure 5. Magnetic field calculation in the HV column region. The B-field is reduced by making the proton source faceplate of ferromagnetic material. The calculations are shown for a distance $10.8 \mathrm{~cm}$ from the beam axis, and $\mathrm{z}=0$ corresponds to the vacuum edge of the ferromagnetic plate.

\section{Gas Pressure Reduction in the HV Column}

The ion source has a dc gas flow of $3-5 \mathrm{sccm}$ while producing design beam. This gas load was originally pumped through eleven $2.54 \mathrm{~cm}$ diameter holes in the base of the HV column. The gas conductance through the HV column was increased a measured factor of three by increasing the number of pump apertures to 72 (cf. Fig. 3). The aperture diameter was decreased to $1.9 \mathrm{~cm}$ to maximize the number of holes and to increase the aspect ratio making the electron suppression easier. 


\section{Summary .}

The condition for the BD of a HV gap is given by $\gamma\left(e^{\alpha d}-1\right)=1$, where $\alpha$ is the Townsend first ionization coefficient and $\gamma$ is the coefficient relating to secondary processes required for initiating a BD. For the LEDA injector HV column, $\alpha$ has been reduced by reducing the magnetic field and pressure in the HV column. Electron current production has been reduced by electron suppression at the beam extraction aperture, pumping apertures, and the ceramic negative triple junctions. The $\gamma$ coefficient has been reduced by attenuating the $\mathrm{x}$-ray flux at the ceramic insulators, and allowing $\mathrm{x}$-rays, electrons, and positive ions to strike only copper and stainless steel within the HV column. Both of these materials are comparatively low producers of secondary electrons.

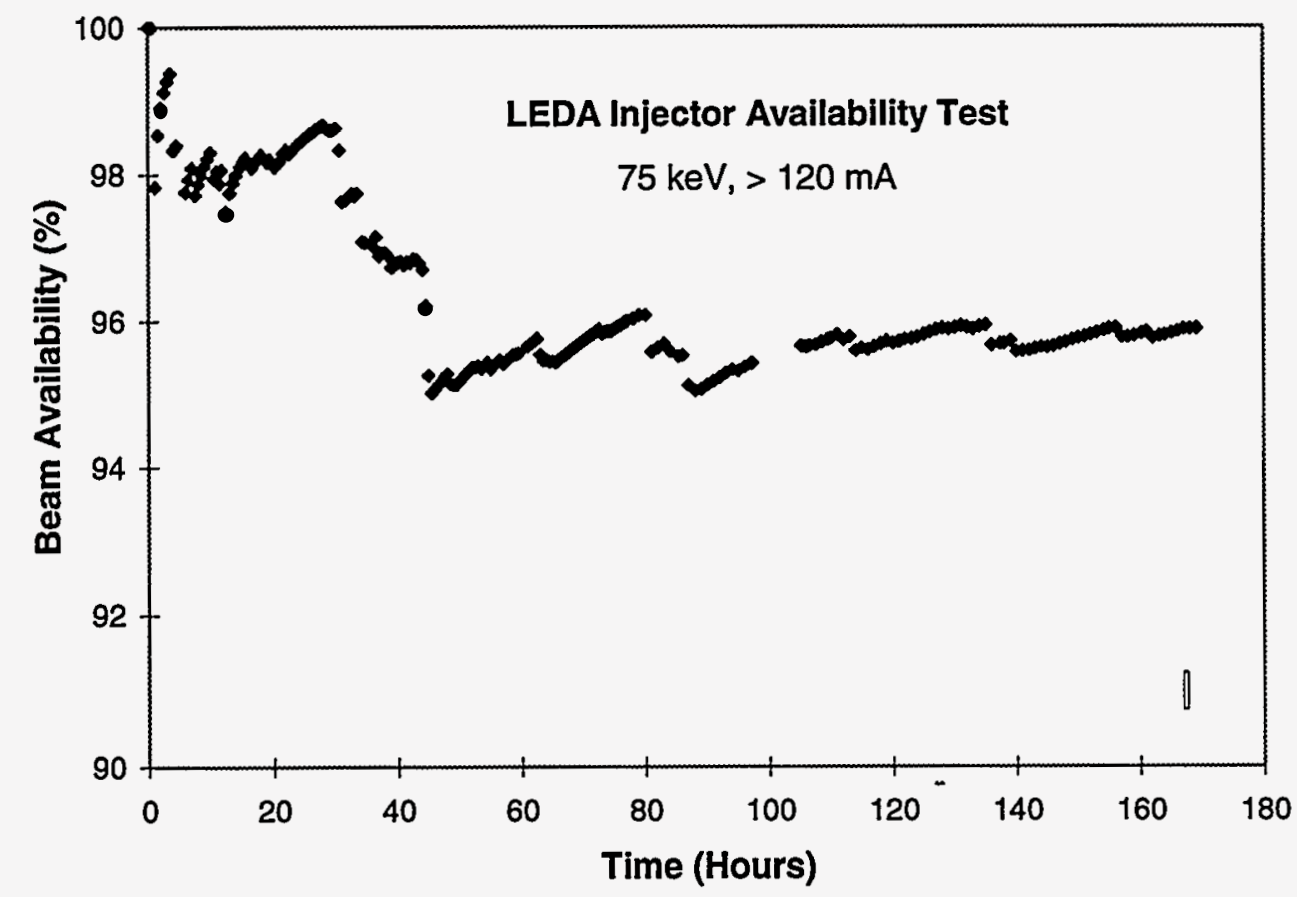

Figure 6. Beam availability results for week-long, 24 hour/day test of the LEDA injector.

A continuous, 168 hour beam availability test was made on the injector requiring dc beam performance of $110 \mathrm{~mA}$ protons at $75 \mathrm{keV}$ energy. The proton fraction during this test was $90 \%$, so the total beam current required was $>120 \mathrm{~mA}$. The results are shown in Fig. 6 where beam availability defined as (beam $>120 \mathrm{~mA}, 75 \mathrm{keV}$ on time)/elapsed time vs. elapsed time is shown. The total injector availability was $96 \%$. The ion source (plasma generator and HV column) accounted for about $2 \%$ while problems with support equipment contributed another $2 \%$ of the $4 \%$ beam off time. 


\section{Acknowledgments}

We thank Jerry Bolme for carrying out the x-ray attenuation calculations on the stainless steel electrodes. We also thank the U. S. Department of Energy for support in carrying out this work.

\section{References}

[1] Terence Taylor and Jozef F. Mouris, Nuclear Instrum. and Methods in Phys. Research A336(1993), 1 .

[2] Dale L. Schrage, Lloyd M. Young, William L. Clark, Thomas O. Davis, Felix A. Martinez, Angela C. Naranjo, and Philip L. Roybal, Proceedings of the 1997 Particle Accelerator Conference, Vancouver BC, Canada (May 12-16, 1997), to be published.

[3] J. D. Schneider and K. C. Chan, Proceedings of the 1997 Particle Accelerator Conference, Dallas, Vancouver BC, Canada (May 12-16, 1997), to be published.

[4] Jack E. Boers, Proceedings of the 1995 Particle Accelerator Conference, IEEE Catalog Number 95CH35843, Dallas, Texas (May 1-5, 1995), 2312.

[5] Joseph Sherman, Andrew Arvin, Lash Hansborough, David Hodgkins, Earl Meyer, J. David Schneider, H. Vernon Smith, Jr., Matthew Stettler, R. R. Stevens, Jr., Michael Thuot, Thomas Zaugg, and Robin Ferdinand, these conference proceedings.

[6] A. von Engel, "Ionized Gases", Oxford University Press, second edition (1965).

[7] L. D. Hansborough, D. J. Hodgkins, E. A. Meyer, J. David Schneider, J. D. Sherman, R. R. Stevens, Jr., and T. J. Zaugg, Proceedings of the 1997 Particle Accelerator Conference, Vancouver BC, Canada (May 12-16, 1997), to be published.

[8] M. J. Kofoid, AIEE Trans. 79 (1960), 999.

[9] James H. Billen and Lloyd M. Young, Proceedings of the 1993 Particle Accelerator Conference, IEEE Catalog Number 93CH3279-7, Washington, D.C. (May 17-20, 1993), 790.

[10] R. A. Anderson and J. P. Brainard, J. Appl. Phys.51(3) (1980), 1414.

[11] Walter H. Kohl, "Handbook of Materials and Techniques for Vacuum Devices", Reinhold Publishing Corporation (1967), 565-566.

[12] E. J. Sternglass, Phys. Rev. 108 (1957), 1. 